\title{
AUTONOMIC HYPERREFLEXIA DURING UPPER EXTREMITY SURGERY
}

\author{
Elliott S. Greene and Joseph L. Seltzer
}

\begin{abstract}
A case is presented of autonomic hyperreflexia in a quadriplegic patient occurring during upper extremity surgery. Tourniquet ischaemia is proposed as the likely causative stimulus. An understanding of the afferent neural pathways involved in this physiological response may be useful in better understanding the subjective phenomena of toumiquet pain in neurologically intact individuals.
\end{abstract}

KEY WORDS: REFLEXES, autonomic hyperreflexia.

AUTONOMIC HYPERREFLEXIA is a physiological response involving massive sympathetic discharge which may occur following high spinal cord transection. Associated with severe hypertension and the sequelae thereof, the reflex is frequently initiated by distension of a hollow viscus. We are reporting a case of autonomic hyperreflexia associated with a surgical procedure on the upper extremity.

\section{REPORT OF A CASE}

A 30 year old $72 \mathrm{~kg}$ male with complete quadriplegia below $\mathrm{C} 6$, with sensation to $\mathrm{C} 6$ intact, presented for a tendon transfer on the right thumb. In addition to spastic quadriplegia with a neurogenic bladder, he had chronic cystitis and bladder calculi. Medications included diazepam $10 \mathrm{mg}$ three times a day and hydrodiuril $25 \mathrm{mg}$ daily. Vital signs were stable: blood pressure $14.6 / 8 \mathrm{kPa}$ ( $110 / 60$ torr), heart rate $80 / \mathrm{min}$ and temperature $37^{\circ} \mathrm{C}$. Physical examination was within normal limits except for diaphragmatic respiration. Haematocrit was 40.9. Electrolytes, glucose and blood urea nitrogen were within the normal range. Past surgical procedures included a cystolithotomy under local anaesthesia. This was complicated by a rise in blood pressure to $27 / 12 \mathrm{kPa}$ (204/90 torr) with bladder distension, which returned to normotensive levels with bladder evacuation. A urinary bladder sphincterotomy under general anaesthesia with thiopen-

Elliott S. Greene, M.D., Fellow in Anesthesiology; Joseph L. Seltzer, M.D., Assistant Professor, Department of Anesthesiology, Upstate Medical Center, Syracuse, New York.

Reprint requests to: Elliott S. Greene, M.D., Department of Anesthesiology, State University of New York, Upstate Medical Center, 750 East Adams Street, Syracuse, New York 13210.

Canad. Anaesth. Soc. J., vol. 28, no. 3, May 1981 tone, nitrous oxide and oxygen with halothane 0.5 per cent was complicated by an atropine responsive sinus bradycardia of $50 / \mathrm{min}$. Blood pressure did not change during this episode.

Although morphine $15 \mathrm{mg}$ intramuscularly and diazepam $20 \mathrm{mg}$ by mouth were given one hour before anaesthesia, the patient was still alert and moderately anxious upon arrival in the operating room. After diazepam $5 \mathrm{mg}$ intravenously, a right axillary brachial plexus block was done. Thirtyfive $\mathrm{ml}$ of bupivicaine 0.5 per cent were injected after obtaining paresthesiae in the hand. An additional $5 \mathrm{ml}$ was injected in a partial ringlet 10 block the intercostobrachial nerve. Initially he had sinus rhythm at a rate of $90 / \mathrm{min}$ and a blood pressure of $16 / 6.6 \mathrm{kPa}$ (120/150 torr). Thirty $\mathrm{mg}$ of diazepam was given intravenously in $5 \mathrm{mg}$ increments for anxiety and restlessness during preparation of the surgical field. The patient became sedated but remained conscious with good spontaneous ventilation. One hour after the axillary block a single upper arm calibrated tourniquet was inflated to $33.2 \mathrm{kPa}$ (250 torr). An incision was made which included the $\mathrm{C}_{5-7}$ dermatomes without evidence of discomfort. During the next 45 minutes the blood pressure remained stable at $16 / 6.6 \mathrm{kPa}(120 /$ 50 torr); however sinus bradycardia developed gradually. At a pulse rate in the low 50's, occasional premature atrial contractions occurred. This proceeded to supraventricular bigeminy of sinus beats alternating with junctional beats. Forty-five minutes after tourniquet inflation and the skin incision, atropine was given in increments of $0.2 \mathrm{mg}$ to a total of $0.6 \mathrm{mg}$ over five minutes. Respiration and colour were good and the patient did not complain of any discomfort. Ten minutes after the last increment of atropine, sinus tachycardia developed $(120 / \mathrm{min})$ with intermittent supraventricular dysrhythmias and 
hypertension to $20 / 13 \mathrm{kPa}(150 / 100$ torr). An erythematous rash was noted over the neck and upper chest 15 minutes later, associated with sinus tachycardia $120 /$ min and hypertension to $32 / 16 \mathrm{kPa}(240 / 120$ torr). At the time the tachycardia and hypertension developed, the tourniquet had been inflated for 60 mintues. The tourniquet was released after 100 minutes of inflation, at which time the blood pressure was $26.6 / 16 \mathrm{kPa}$ (200/120 torr). No additional medication was given. Total fluid administered during operation was $850 \mathrm{ml}$ of lactated Ringer's solution with five per cent dextrose. A urinary catheter was draining well, ruling out bladder distension. Upon arrival in the recovery room the patient had persistent tachyarrhythmias and hypertension. After one-half hour, the erythema recurred and he complained of a severe headache. At this time, 90 minutes after the atropine had been given, antihypertensive treatment with intravenous sodium nitroprusside (SNP) was started. With doses of $60-75 \mu \mathrm{g} / \mathrm{min}$ controlling the blood pressure at $16 / 10.6 \mathrm{kPa}$ (120/80 torr) repeated attempts to reduce SNP resulted in recurrent hypertension. Headache and erythema cleared after 45 minutes; however, dysrhythmias continued during three hours of antihypertensive therapy. Incisional pain developed seven hours after the axillary block and was unassociated with changes in vital signs. After $4 \frac{1}{2}$ hours SNP therapy was discontinued. Blood pressure was 18.6/ $10.6 \mathrm{kPa}$ (140/80 torr) with sinus rhythm of $80 / \mathrm{min}$. The total duration of hypertension was $5 \frac{1}{2}$ hours. The remainder of the hospital course was unremarkable with stable vital signs and no further erythema or headache.

\section{Discussion}

Autonomic hyperreflexia is usually associated with transections of the spinal cord at the T5 level or above; 85 per cent of all quadriplegics develop autonomic hyperreflexia. ${ }^{1.2}$ The classic occurrence involves bladder spasm or distension; however stimulation of other viscera (bowel, uterus, kidney, and the biliary tree) as well as tactile, proprioceptive and thermal stimulation to the skin can also trigger the reflex. Cord lesions which interrupt descending inhibitory fibers may result in somatic hyperreflexia (mass reflex), which includes autonomic and motor hyperreflexia. Autonomic hyperreflexia may occur with recovery of reflex activity after the initial spinal shock period of one to three weeks. ${ }^{3}$ Autonomic hyperreflexia is thought to arise from stimulation of afferent fibers of the isolated spinal cord below the lesion. Since this is uninhibited by normal central nervous system regulation, it results in massive reflex sympathetic hyperactivity with complicating cardiovascular instability. ${ }^{4.5}$ Clinical manifestations of autonomic hyperreflexia may include sweating, flushing, severe headaches, vasodilation above and vasoconstriction below the lesion, paroxysmal hypertensive crisis, bradycardia and dysrhythmias, pilomotor spasm, respiratory difficulty, alterations in consciousness and convulsions. ${ }^{2,4.6}$

Indications for choosing regional anaesthesia were avoidance of perceived pain from dermatomes above the cord lesion and the potential problem of autonomic hyperreflexia from surgical stimulation below the lesion. Good muscle relaxation was provided and potential complications of general anaesthesia in patients with high level cord lesions were avoided. ${ }^{3} \mathrm{~A}$ large dose of diazepam was required; however, it only produced mild sedation. We suspect that this was the result of tolerance induced by the patient's chronic use of diazepam.

In healthy subjects a peak increase of mean heart rate from $60 / \mathrm{min}$ to $82 / \mathrm{min}$ occurred less than three minutes after $0.6 \mathrm{mg}$ atropine intravenously. ${ }^{7}$ In spinal anaesthesia with a T5 sensory level intravenous atropine $0.4 \mathrm{mg}$ increased the mean heart rate of $78 / \mathrm{min}$ by eight and nine per cent at one minutes and five minutes respectively and produced negligible effects on mean arterial pressure. ${ }^{8}$ In contrast our patient's tachycardia and hypertension developed 10 minutes after atropine and both the heart rate and blood pressure rose by 100 per cent. In addition, the patient received atropine during a previous anaesthetic without untoward effects. Although bradycardia is classically described with autonomic hyperreflexia tachycardia has been reported. ${ }^{9}$ Furthermore, we question whether a single intravenous dose of atropine $0.6 \mathrm{mg}$ would be responsible for $5 \frac{1}{2}$ hours of hypertension, although it certanly may have contributed to the initial episode.

The administration of atropine may result in erythema caused by histamine release. Histamine release, however, would be inconsistent with the associated hypertensive response in this patient. In particular, we note the distinction between histamine induced vasodilation, flushing and hypotension and the likely situation here of vasodilation above and vasoconstriction below the level of cord injury. Cutaneous temperature measurements might have helped to document 
vasoconstriction below the level of the cord lesion. In addition, the recurrent episodes of erythema, as much as 90 minutes after the atropine, are consistent with the flushing and vasodilation seen in autonomic hyperreflexia. Atropine has not, to our knowledge, been reported to cause autonomic hyperreflexia, but it has not been eliminated as the precipitating cause in our patient.

Tourniquet pain is described as arising after 45-60 minutes of ischaemia. It ischaracterized as a dull ache which is poorly localized in the extremity and outlasts the provoking stimulus. Anoxia may be the aetiology. ${ }^{10-12}$ It is generally accepted that somatic pain is carried over small myelinated A-delta (pin-prick) fibers and small unmyelinated $C$ fibers. The latter are responsible for true pain and probably for tourniquet pain. ${ }^{11-13}$ Tourniquet pain during spinal anaesthesia has been hypothesized to occur on the basis of unblocked afferents." C-fibers innervating the vasculature may travel by sympathetic trunks and enter at levels other than the corresponding somatic roots. ${ }^{14}$ Autonomic fibers may also enter blood vessels near the sympathetic trunks and travel to the vessels' peripheral distribution. ${ }^{15}$ The afferent fibers might enter the blood vessels proximal to the site of local anaesthetic block. Perhaps stimulation of these fibers may be responsible for tourniquet pain encountered occasionally in neurologically normal patients in the presence of a brachial plexus block. If this afferent mechanism were involved in our patient awareness of tourniquet pain was perhaps not manifested because most of the afferents entered below the cord lesion. Afferent nerve stimulation from skin and superficial sources was an unlikely cause of autonomic hyperreflexia since the onset was not related to surgical incision and the patient did not feel pain until late in the recovery room period. Persistent autonomic hyperreflexia after tourniquet release is not fully understood. Autonomic hyperreflexia characteristically sub. sides when the initiating cause is removed. If the cardiovascular instability in our patient was related to ischaemia secondary to tourniquet infla. tion, we question why it persisted for several hours after deflation of the tourniquet.

Anaesthetic management of autonomic hyperreflexia has been widely discussed. . $^{2,4.116-19}$ Controversy exists concerning the primary anaesthetic approach to patients with high cord lesions and management of autonomic hyperreflexia if it occurs. Blocking the afferent stimuli using a regional technique has been a successful ap- proach. There may, however, be some difficulty in assessing the level of block. General anaesthesia has been used successfully in some cases. ${ }^{19}$ Others report a high incidence of autonomic hyperreflexia and associated dysrhythmias during halothane anaesthesia and question the use of a myocardial depressant in patients with increased systemic vascular resistance. ${ }^{17}$ Enflurane anaesthesia has not been well studied. A nitrous-oxide, oxygen, narcotic technique would probably not be a satisfactory method for controlling hypertensive crisis. Antihypertensives including sodium nitroprusside, trimethaphan, and pentolinium have been used successfully to treat or prevent autonomic hyperreflexia.

In summary, we have presented a case of autonomic hyperreflexia occurring during upper extremity surgery in a quadriplegic patient. The precise explanation is elusive; however either tourniquet ischaemia or, less likely, atropine may be the cause.

\section{REFERENCES}

1. Cilberti, B.J., Goldfein, J. \& Rovenstine; E.A. Hypertension during anesthesia in patients with spinal cord injuries. Anesthesiology 15: 273279 (1954).

2. Guttman, L. \& Whitteridge, D. Effects of bladder distension on autonomic mechanisms after spinal cord injuries. Brain 70: 361-404 (1947).

3. Desmond, J. Paraplegia: Problems confronting the anesthesiologist. Canad. Anaesth. Soc. J. $1 \%$ : 435-451 (1970).

4. Johnson, B., Thomason, R., Pallares, V., et al. Autonomic hyperreflexia: A review. Milit. Med. 140:345-349 (1975).

5. KURNick, N.B. Autonomic hyperreflexia and its control in patients with spinal cord lesions. Ann. Intern. Med. 44: 678-686 (1956).

6. ARIef, A.J., Tigay, E.L. \& Pyzik, W.S. Acule hypertension induced by urinary bladder distension. Arch. Neurol. 6: 248-256 (1962).

7. Grayenstein, J.S. \& Perkins, H.M. The effect of neostigmine, atropine and ephedrine on heart rate in man. Anesthesiology 27: 298-303 (1966).

8. WARD, R.J., KENNEDY, W.F. JR., BONICA, J.J., it al. Experimental evaluation of atropine and vasopressors for the treatment of hypotension of high subarachnoid anesthesia. Anesth. Analg. 45:621629 (1966).

9. Basta, J.W., Niejadlik, K. \& Pallares, V. Autonomic hyperreflexia: Intraoperative control with pentolinium tartrate. Br. J. Anaesth. 49: 1087-1090 (1977).

10. Egberr, L.O. \& Deas, T.C. Cause of pain from a pneumatic tourniquet during spinal anesthesia. Anesthesiology 23: 287-290 (1962).

11. DEJong, R.H. Tourniquet pain during spinal anesthesia. Anesthesiology 23: 881-882 (1962).

12. Bowsher, D. Pain pathways and mechanisms. Anaesthesia 33: 935-944 (1978). 
13. DEJong, R.H. Tourniquet pain. Anesthesiology 25: 247-248 (1964).

14. Kuntz, A. Afferent innervation of peripheral blood vessels through sympathetic trunks. South. Med. J. 44: 673-678(1951).

15. Gray's Anatomy 35th British Edition. Edited by Warwick, R. - Williams, P.L. Philadelphia, W.B Saunders, pp. 1065-1083 (1973).

16. Thorn-Alquist, A.M. Prevention of hyperiensive crises in patients with high spinal lesions during cystoscopy and lithotripsy. Acta Anaesthesiol. Scand. (Suppl). 57: 79-82 (1975).
17. Alderson, J.D. \& Thomas, D.G. The use of halothane anaesthesia to control autonomic hyperreflexia during trans-urethral surgery in spinal cord injury patients. Paraplegia /3: 183-188 (1975).

18. Texter, J.H. JR., Reece, R.W. \& Hranowsky, $\mathrm{N}$. Pentolinium in the management of autonomic hyperreflexia. J. Urol. /16: 350-351 (1976).

19. Drinker, A.S. \& Helrich, M. Halothane anesthesia in the paraplegic patient. Anesthesiology 24: 399-400 (1963)

\section{RÉSUMÉ}

Les auteurs présentent une observation d'hyperréflexie autonome chez un quadriplégique survenue pendant une intervention au membre supérieur. L'ischémie par le garrot fut le facteur déclanchant probable. La connaissance des voies afférentes nerveuses impliquées dans cette réponse physiologique peut être utile à une meilleure compréhension du phénomène subjectif de la douleur causée par le garrot chez les malades qui sonı neurologiquement intacts. 